\title{
Conversion of a conventional to a digital lecture under the conditions of Covid19 - an example from a bachelor lecture on finishing, dyeing \& printing
}

\author{
Boris Mahltig* \\ Mönchengladbach, Germany \\ *Corresponding author E-mail address: boris.mahltig@hs-niederrhein.de
}

Niederrhein University of Applied Sciences, Faculty of Textile and Clothing Technology, Webschulstraße 31, 41065

\section{INFO}

CDAPT, ISSN 2701-939X

Peer reviewed article

2021, Vol. 2, No. 2, pp. 173-186

DOI 10.25367/cdatp.2021.2.p173-186

Received: 05 December 2021

Accepted: 13 December 2021

Available online: 16 December 2021

\begin{abstract}
Due to the Covid-19 pandemic situation during the years 2020 and 2021 , the necessity occurred to convert conventional university lectures into digital ones, to avoid personal contacts between people and by this minimizing the spreading of the disease. Beside lectures, also exams have to be transferred to minimize personal contacts. This paper reports on a lecture in a bachelor course with more than 100 students and its conversion to digital format. The lecture is related to textile finishing processes especially to dyeing and printing. The experience get during the digital lecture are compared with the results gained during the last decade with the same lecture in conventional style. Main tools of the digital format are video conferences and digital worksheets. Challenging are the contact to students by e-mail and the time management of the students especially during the final digital homework. In conclusion, digital lecture and exam are valuable tools to increase the number of participating students and their success in the exam. These tools could be also used successfully in post-corona times especially for lectures given for experienced students in higher semester.
\end{abstract}

\section{Keywords}

digital teaching,

alternative exams, video conference, finishing,

dyeing, printing
(C) 2021 The authors. Published by CDAPT.

This is an open access article under the CC BY-NC-ND license https://creativecommons.org/licenses/ peer-review under responsibility of the scientific committee of the CDAPT.

(C) 2021 CDAPT. All rights reserved.

\section{Introduction}

During a conventional lecture, students and lecturers meet in the same room personally. The lecturer uses different tools to transfer knowledge and skills to the students. In the teaching situation, the 
personal presence is important and the success of the teaching process is directly related to the rhetoric skills, preparation and used methods of the lecturer.

Because of the Covid19 pandemic situation, new regulations appear in German universities which forbid conventional lectures with presence and meeting of students to avoid the spreading of this disease. For this, there was the clear demand to develop new lecture concepts without the demand of personal contacts. One possible tool can be here the development of a digital lecture, where the contact of professors and students is made by an online tool, such as e.g. a video conference. During the recent months, teaching persons worldwide developed and promoted various digital tools for education in university [1-4]. In fact, the pandemic situations offered the opportunity to try new education concept with a digital teaching format. A good overview on different digital formats is given by Schwarz et al. [1].

Additional to the modification of the lectures, the examination process also has to be organized in a way that personal contacts between persons are minimized. This issue is less discussed in recent publications and for this a special view on digital exams and student performance is given by the present article. In former semesters, usually written exams are done with duration between one to two hours. During written examinations, hundreds of students can be managed in the exam in a short period of time. For smaller courses containing up to 30 students, such a written exam can be easily converted to an oral exam by video conference. However, due to the time capacity this is not possible for larger groups. Further, often some students fear the direct confrontation during an oral exam and prefer for this reason written exam [5]. This statement is even valid for experienced students in master courses [5].

The current paper reports on a bachelor course with around 100 participating students and its conversion from a conventional to a digital lecture. Also, the exam is transformed to a digital format. A comparison of the digital winter semester 2020/21 to former nine years of conventional teaching is given. It will be shown that several tools can be successfully used to increase the number of participating students and to enhance also their success in the exam, finally.

\section{Background and general conditions of the lecture}

The lecture described in this paper is named in the curriculum as "Finishing 1" and aims mainly on the topics dyeing and printing. It is a bachelor lecture regularly given for students in the 3rd semester. This lecture is completely told in English language and part of the English bachelor course "Textile \& Clothing Management" (TCM). Main contents are coloration, different types of dyes and pigments, fiber-dye interaction, dyeing machines, printing techniques, printing recipes, fastness properties and testing procedures. In regular semesters, this lecture is finished with a written exam, which is also done in English language. This exam has to be done together with a second lecture named "Finishing 2". Both finishing lectures are part of the same module and have to be passed together. This term "module" is especially used at German universities to describe two or more lectures which belong together and which are also examined together. The lecture Finishing 2 is related to finishing topics which are not in the area of dyeing and coloration of textiles, as e.g. water-repellent finishing or flame-retardant treatment. The exam is offered in the end of the winter semester - usually in February. It can be repeated two times in the following summer (July or September). The students have to register officially to the exam but there are no consequences, if they do not join the exam even in case of registration. For this, the number of registrations is often high but the number of students finally join the exam is significantly lower.

The long-term development of the lecture over the decade from the year 2012 to 2021 is shown in the Figures 1 and 2. Figure 1 presents registered students and the students which finally participate and pass. It is distinguished in Figure 1 between the number of students, who got in the lecture finishing 1 more than 24 points and the students which finally pass both finishing lectures. For the lecture finishing 1 in maximum 50 points can be received, so students who get in this lecture more than 24 points have passed this lecture. Finally passed students gained in both lectures finishing 1 and finishing 2 at least 50 points from 100 maximum points. The long-term average of registered students is 101 persons; this 
number covers nearly all students in this study course per semester. There is a continuous decrease in registered students from 2012 to 2020 , which is related to a general decrease in student number of this study course during the last decade.

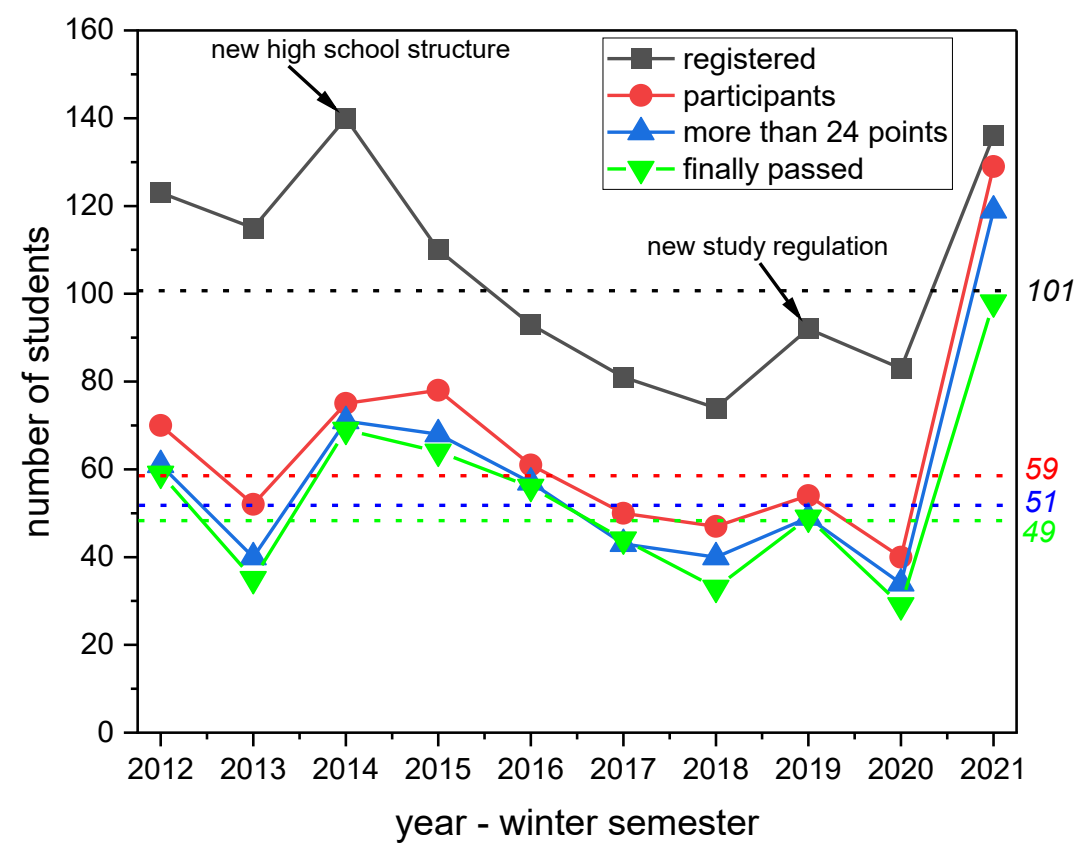

Fig. 1 Development of student number over a full decade. Compared are the students which are registered to the exam at the end of the winter semester, joining the exam and having a successful result. The average values are shown as dotted lines and given as numbers on the right side. Also, two events with possible influence on the student numbers are indicated by arrows.

There are two maxima for registered students in the years 2014 and 2019, which can be explained by two different events. These events are a new high school structure in Germany and a new study regulation introduced in the faculty. The mentioned new high school structure leads to significantly higher numbers of young people with the permission for entering the university in the years around 2014 .

It is clearly seen that a significantly lower number of students participate in the exam compared to higher number of registration (Figure 1). Due to the strong work load during the semester, the possibility of free resignation and the chance to join the following exams in summer, the low number of participating students is explained easily. A positive issue is that more than $80 \%$ of participating students passed finally the exam. Here, figure 1 distinguishes between students having more than 24 points in the lecture Finishing 1 and the students which finally pass both lectures Finishing 1 and Finishing 2 . It is clear, that there is no significant difference during the years 2012 to 2020 . Both finishing lectures and their exams have probably similar difficulties and demands.

Figure 2 presents the average of gained points per student for each year over the long-time view from 2012 to 2021. In maximum 50 points can be gained and 25 points are the minimum to pass. In figure 2 it is distinguished between the average values of all students and the average of the students gained 25 or more points. The long year average values are 35.2 points and 37.7 points, respectively. For both values over long-time a decrease in the gained points is observed. This decrease is not very strong and there is no simple explanation for it. 


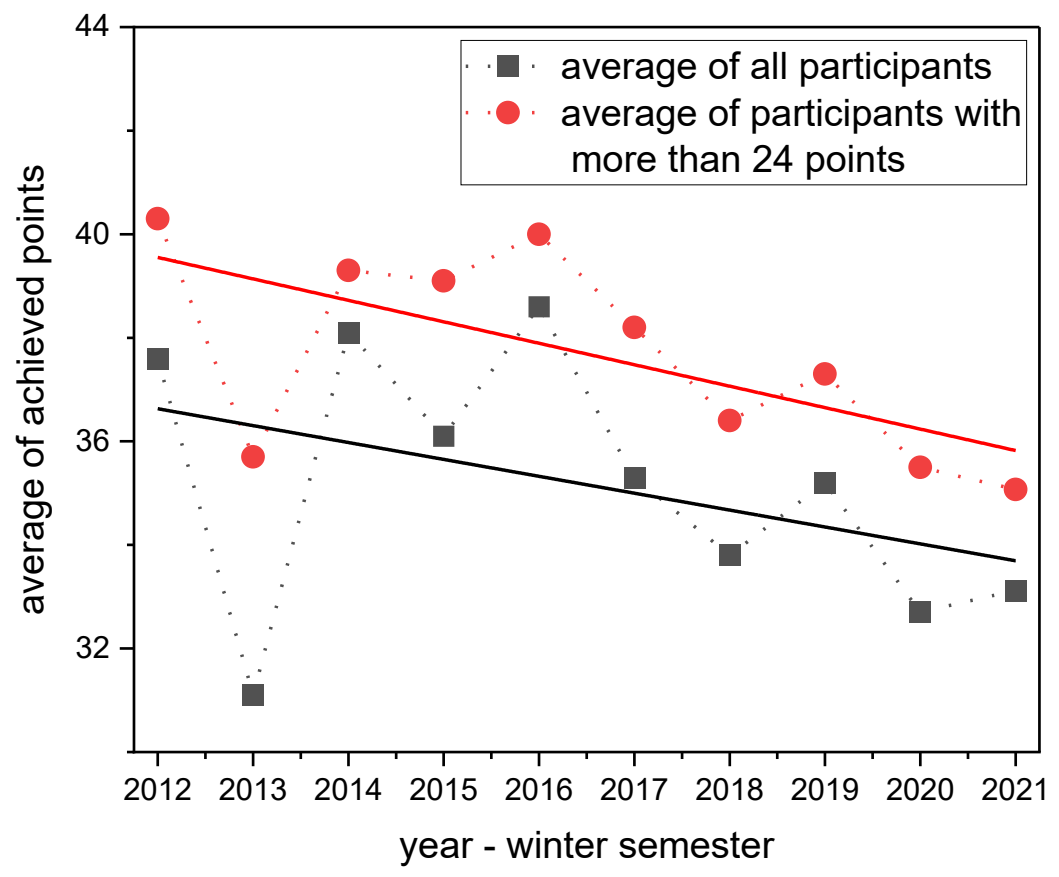

Fig. 2 Development of exam results over a full decade. Compared are the average of achieved points from all participating students (maximum points 50) and the averages from participants with more than 24 points. For both values, a linear fit is shown in the graph.

It could be estimated that over the years the questions in the written exams get more difficult. In first years, simple questions are given, which are varied in following years to introduce new questions. These variations are often related to new combinations and background knowledge, which need a deeper understanding of the topics.

Figure 3 gives a view on the students registered for the current exam in the year 2021 in relation to their duration of study. There are nearly 70 students from the 3rd semester. They join the exam according to the study plan. However, in this 3rd semester there are in total 86 students enrolled, so 16 students are missing in the exam registration. This loss of students also occurs in other bachelor lectures during this semester and is probable caused by the conditions of pandemic situation. During this situation the connection of students and university gets lost, because of the lack of physical presence. Additionally, there are also many students from higher semesters registered, which have not passed this exam earlier. While the registered 5th semester students are still in the frame of regular study duration, students with higher semester numbers have a significant delay in study. It is remarkable that there are still five students with higher semester numbers between 15 to 19 semesters. Such a duration of study is more than the twice the regular study duration of 7 semesters of the bachelor course. It should be remarked that in German study system there is no formal limit of study duration. If a student does not join an exam and does not fail, he cannot be removed from university. For this, there are always few students who exhibit very high semester numbers. Often these students are already working in different kinds of companies and entered the job market before finishing the bachelor certificate. 


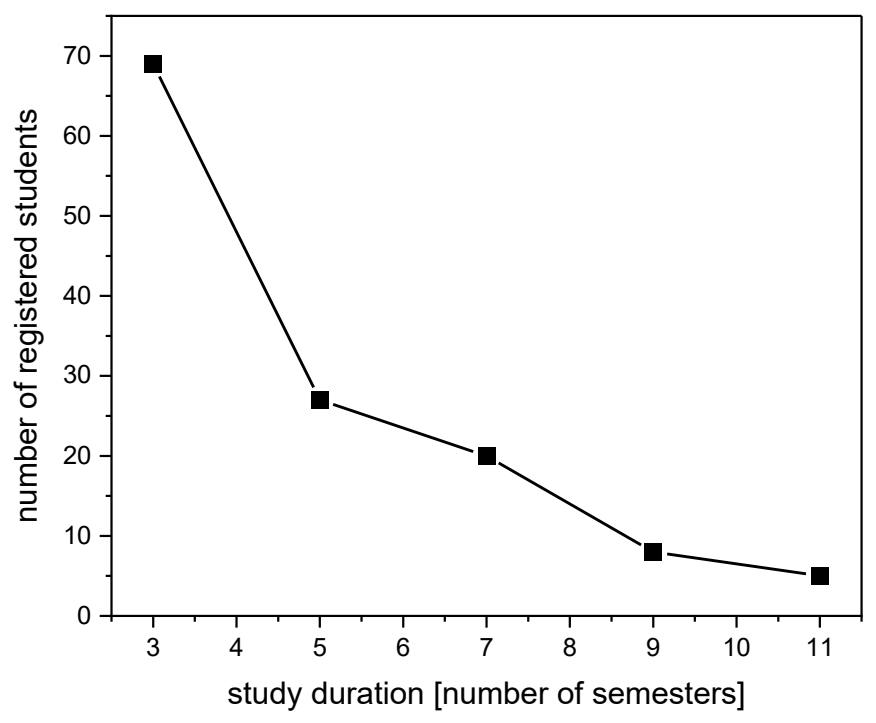

Fig. 3 Number of students registered for the exam of winter semester in year 2021 as function of their study duration in number of semesters. Five students with study duration between 15 to 19 semesters are not mentioned in this graph

\section{Digital lecture}

The key element of the digital lecture (dyeing \& printing) was the use of a video conference tool (Zoom). On a fixed date each week (90 minutes) the conference was opened and offered for the students during the semester. In total, a number of 12 events are offered. The students are invited by e-mail to these events 15 minutes before starting the session and they are free to join. The invitation list covers around 150 students with their e-mail addresses. Instead of a script, a text book of Roger Wardman about textile coloration was recommended to use [6]. The topics for the following week were announced by e-mails with a hint on related pages and chapter in this book. Further, also some online available journal articles are recommended for different topics. Especially used for the description of vat dyes and sulfur dyes are the papers of J. R. Aspland $[7,8]$. For explanation of reactive dyes two papers are recommended $[9,10]$.

For comparison of the two processes spin-dyeing and batch-dyeing of yarns, a video from the company Clariant was used. The vocabulary used in this video was explained step by step and the main statements of the video were discussed. A special view was given to the point of view of the producer of this video and his interest as supplier of spin dyed fibers. In contrast to the video statements, also the opposite arguments for batch dyeing processes are given. Besides the technical understanding, it was the main aim that the students learn that each process has advantages and has to be chosen according to the actual challenges and demands.

Main statements related to the content of each lecture were fixed as a summary on a pdf-file and send back to all students by e-mail after the lecture together with the topics for the following week. By this procedure a script paper was developed during the semester and offered as data base for the students. Additional to the lecture, also worksheets with three or four questions are sent three times to the students by e-mail. These worksheets are also part of the examination and they are discussed in detail in the next section.

Figure 4 gives an overview on the students joining the video conference and submitting the worksheets. The first two lectures started with around 100 students, this is the normal size of the class. Following weeks, around 60 to 70 students joined. Before the Christmas holidays, the student number decreased again and increased finally again with the last lecture, where a preparation to the final exam was offered. 


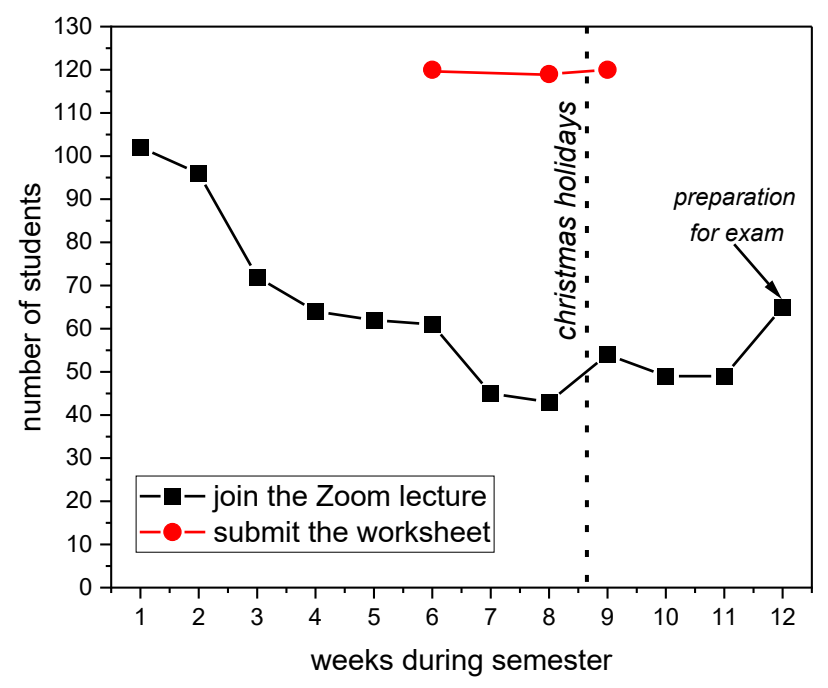

Fig. 4 Development of students participating to digital lecture and worksheets during the winter semester 2020/2021.

This curve is also typical for conventional lectures of the bachelor course given in the years before. Usually, the lectures are offered as open events and there is no duty for the students to appear. For this, in the beginning of each semester a big number of students join to pick up scripts, materials, information and check the general conditions. Later in the semester, only bachelor students join who like to follow the lecture. Especially students from higher semesters who took part in the same lecture last year do not join the lecture continuously during the complete semester. In the current digital semester, there were mainly two types of students joining continuously during the complete semester. At first, these are young students of the 3rd semester. Second, there are older students with a strong delay in study, who need to finish this lecture as one of the last in their bachelor study. However, from the data collected, a correlation between the participation of Zoom lectures and the exam performance of the students cannot be made.

During the current digital semester, all students have of course the advantage that they get directly after the lecture event the complete summary of the content by e-mail. Compared to the number of students joining the lecture, the number of students submitting the worksheets is high with around 120 persons. However, it has to be remarked that these are not always the same persons, even if the total number of submissions is nearly stable.

During each lecture event by video conference, at first headlines and topics are noted on a word file visible for the students. Following, remarks are simultaneously written on the word-file and by this visible and fixed for the students. An advantage of this procedure is also that it decelerates the speed of the lecture to a convenient level. Further, questions given to the students are written down here. Related to these questions the students can answer by using the chat-function of the online-program of the video conference. One example is given here in Figure 5. In the first lecture the introducing question "What is a dye?" was given to the students. The corresponding answers submitted by chat-function are shown in Figure 5. Usually if takes a few minutes to wait for the answers and collect them. These answers are also copied to the word file and are by this part of the final lecture documentation. The answers are discussed in the lecture and main points of discussion are also documented. 


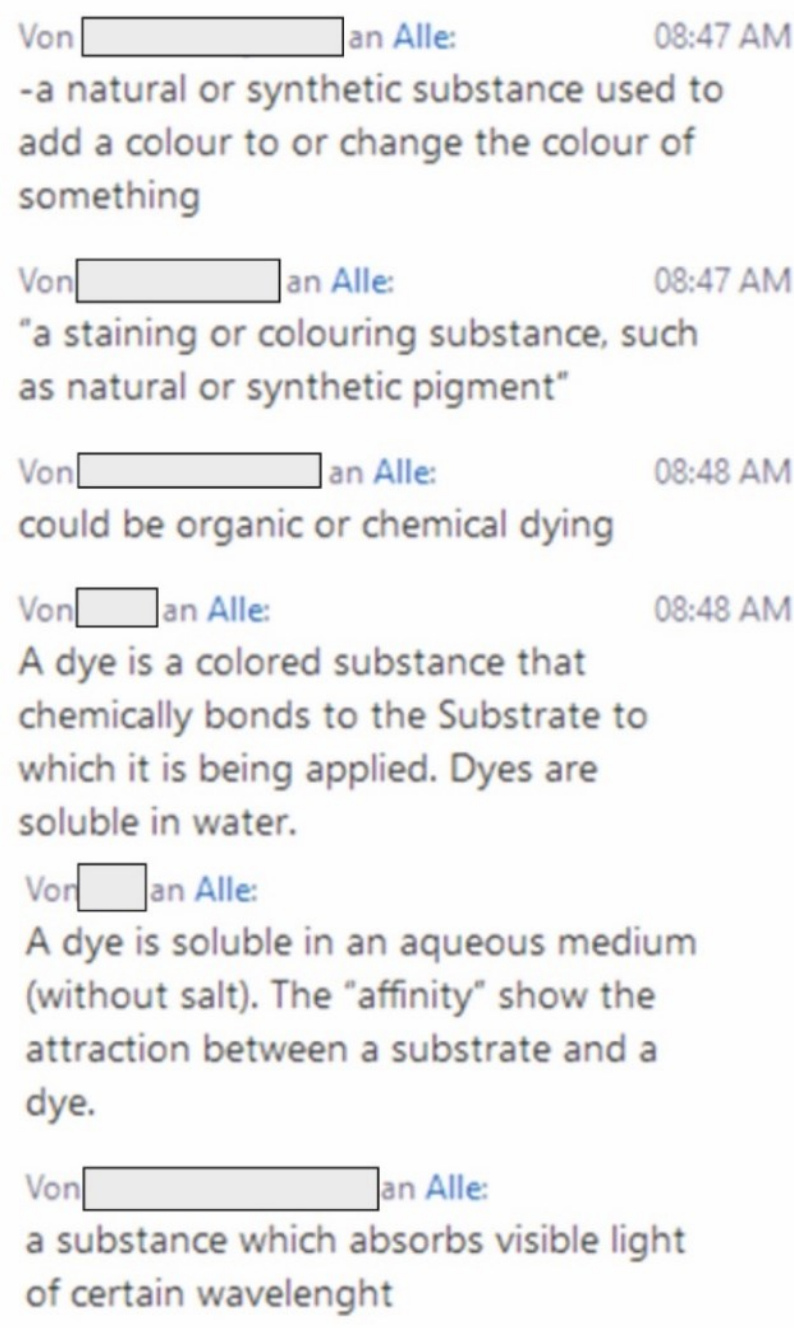

Fig. 5 Overview on some student answers by chat function related to the question "What is a dye?"

In fact, this question for a dye was made as introduction, before a detailed definition of a dye was given in the lecture. For this, by the answers a certain documentation on the knowledge of the students before starting the course is given. By view on these answers it is clear that the students have already a certain idea, what a dye is and how to describe it and its properties. It is a usual situation that the students know the term but they have problems to formulate a clear definition and explanation for an issue. In this actual case, only the last answer documented here is related to a clear definition. Here also, the words "absorb" for the up-take of light and the term "visible light" are mentioned. This last answer was given by a student in higher semester (15th semester), who has already repeated the lecture several times. The mentioning of both terms "absorption" and "visible light" was then used as starting point for further discussion and definitions, because these terms are important for the further lecture and they are necessary for the understanding of the whole definition.

To structure the results of the lecture, especially tables are developed that summarize the main results. One example for such a summarizing table is shown in Table 1. Here, three different types of fibers are compared with their properties influencing the dyeability with acid dyes. 
Table 1. Example for a table developed during the lecture describing the different dyeability with acid dyes for three different fiber materials.

\begin{tabular}{|c|c|c|c|}
\hline Fiber & $\begin{array}{l}\text { Interaction to } \\
\text { water / up-take } \\
\text { of humidity }\end{array}$ & Number of amino groups (+) & General statement for dyeing \\
\hline Nylon & $4 \%$ & Only amino end groups & \multirow{3}{*}{$\begin{array}{l}\text { Increasing water affinity (better up-take } \\
\text { of dye bath); } \\
\text { Increasing number of amino groups, you } \\
\text { have more anchor points to the acid } \\
\text { dye, the dyeing is easier }\end{array}$} \\
\hline Silk & $>9 \%$ & $\begin{array}{l}\text { Amino end groups and few additional } \\
\text { amino groups in the side chains }\end{array}$ & \\
\hline Wool & $>9 \%$ & $\begin{array}{l}\text { Amino end groups and many additional } \\
\text { amino groups in the side chains }\end{array}$ & \\
\hline
\end{tabular}

\section{Worksheets and examination}

\subsection{Intermediate worksheets}

The intermediate worksheets were distributed by e-mail at three different dates during the semester. The students had two weeks to finish the worksheets and to send them back by e-mail. Each worksheet counts with maximum 10 points for the complete exam. For this reason, the number of returned worksheets is with 120 pieces quite high (Figures 4 and 6). Worksheets submitted after the deadline are not counted. As shown in Figure 6, most worksheets are sent back during the last day before deadline. Even for the third worksheet which has to be worked on during the Christmas holidays, there are no higher numbers of submitted worksheets earlier than two days before the deadline. It cannot be stated that students who submit earlier have significantly better or worse performance. Most students gained between 8 and 10 points per worksheet (Figure 7). However, it was quite rare that a student gained in all three worksheets the high score. Also, there are some students who submitted only one or two of the worksheets. Few students submitted no worksheet at all.

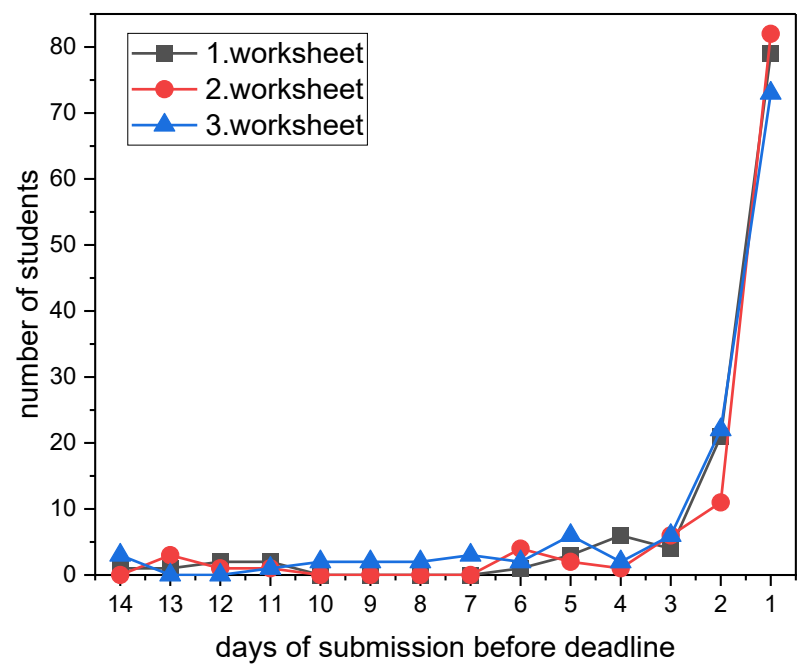

Fig. 6 Development of submitted worksheets in relation to the deadline for submission. Compared are the numbers of students who submit the different worksheets. 


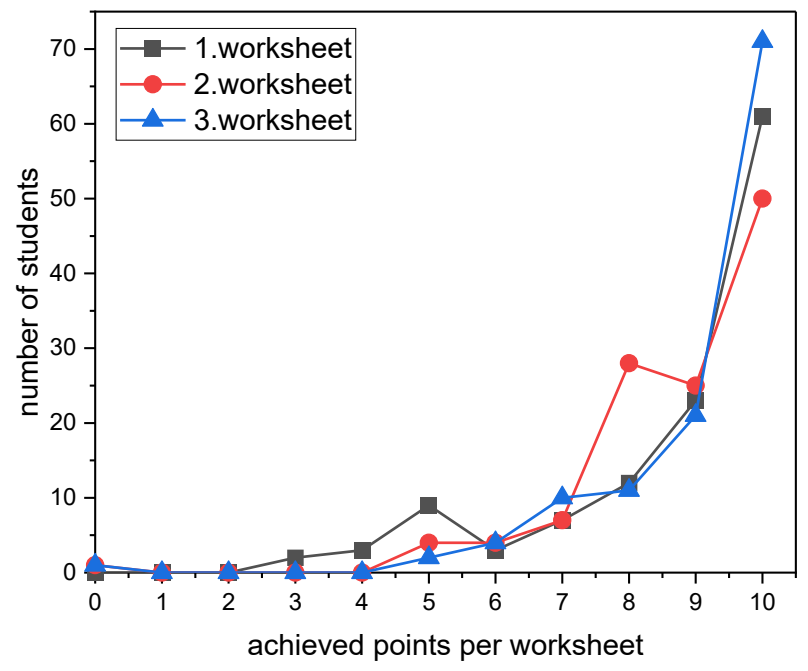

Fig. 7 Gained worksheet results. Compared are the numbers of students who achieve a certain number of points (maximum 10 points are possible).

The first and second worksheets contain four questions, while the third worksheet contains only three questions. Some examples for different questions given in the worksheets are presented in Table 2. Besides the question, also the intention for background understanding is mentioned in Table 2. Main points are here the structure related thinking and fiber/dye interaction. Of course, the students can use books and full internet source to solve these questions. With this background it is quite surprising that not all students submit all worksheets with high score.

Table 2 Examples for different questions in the worksheets. Additional to the questions also the intention for the main understanding is given.

\begin{tabular}{lll}
\hline $\begin{array}{l}\text { Work- } \\
\text { sheet }\end{array}$ & Question & Intention for understanding \\
\hline $\mathbf{1}$ & $\begin{array}{l}\text { Draw the chemical structure of "leuko-indigo" } \\
\text { and explain its difference to the dye indigo. }\end{array}$ & vat dyes with indigo basic structure \\
$\mathbf{2}$ & $\begin{array}{l}\text { Draw the chemical structure of a reactive dye. } \\
\text { Mark the reactive anchor group and suggest a } \\
\text { pH values which could be used for the related } \\
\text { dye bath. }\end{array}$ & $\begin{array}{l}\text { dyeing with reactive dyes and the difference } \\
\text { between chromophore and reactive anchor } \\
\text { group }\end{array}$ \\
$\begin{array}{l}\text { Mention and discuss advantages and } \\
\text { disadvantages of spin dyeing and bath dyeing } \\
\text { of polyester yarns. }\end{array}$ & $\begin{array}{l}\text { spin dyeing with its advantages and } \\
\text { disadvantages }\end{array}$ \\
$\begin{array}{l}\text { Why does wool have a higher affinity to acid } \\
\text { dyes compared to nylon? Please give } \\
\text { arguments related to the chemical structure of } \\
\text { both fiber types. }\end{array}$ & $\begin{array}{l}\text { principles of acid dyeing and affinity of different } \\
\text { fiber to acid dyes, relation to Table } 1\end{array}$ \\
\end{tabular}

The given question "Draw the chemical structure of a reactive dye. Mark the reactive anchor group ..." is quite simple and was also part of a discussion in the lecture before. However, it was not solved by all students correctly. Most students $(73 \%)$ solved this question by drawing a quite prominent reactive dye with chlorotriazine or fluorotriazine reactive anchor group. This example was formerly discussed in lecture and is prominently presented in the recommended book. Some other students $(21 \%)$ draw 
reactive dyes with a reactive vinylsulfone group. However, some of these students were not able to identify this reactive anchor group. This type of dye was less discussed in the lecture but is fully explained in the recommended book. Surprisingly a small group of students (5\%) mention a quite special reactive dye with a bromoacryl amido group as reactive anchor. The chemical structures of those reactive anchor groups are exemplarily shown in Figure 8 . In this case, no student was able to identify this reactive group. Probable, the students copy the structure of this dye without further understanding or reading from an internet web-page of a producer of textile chemicals. To avoid such a copy \& paste working style is probable one big challenge during a digital lecture and digital examination situation.

By view on all the worksheet results, it is quite clear that two weeks duration and free sources (internet and books) does not give a $100 \%$ guarantee that the student answers are fully correct.

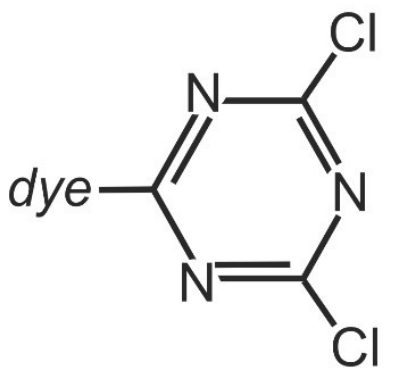

dichloro triazine<smiles>O=S(=O)(O)CCOS(=O)(=O)O[Na]</smiles>

yinyl sulfone<smiles>Oc1nc(F)nc(P)n1</smiles>

fluoro triazine<smiles>C=C(Br)C(=O)NOC1CCCCC1</smiles>

bromo acrylamido

Fig. 8 Chemical structures of different anchor groups typical for reactive dye stuffs.

\subsection{Final worksheet}

The final worksheet was taken as a substitute for an originally planned written examination. It counts 20 points from 50 points in total. Due to the similarity to a conventional exam, the duration of processing of this final worksheet was set to 90 minutes with additional 15 minutes at the beginning and the end to organize technical issues. In this time, the final worksheet of the lecture Finishing 1 and a complete worksheet for the lecture Finishing 2 have to be processed by the students. The questions were sent by e-mail to the students. They had to put the answers on a piece of paper by hand, made a photo copy and sent them back until a given deadline. This process is quite comfortable and flexible, because minimal technical devices like a smartphone or a tablet computer are enough to run the process. The number of student submissions in relation to the deadline is shown in Figure 9. The most students submit in the last six minutes before deadline. Further, there was no student who submitted earlier than 10 minutes before deadline. The time management of the students and their trust in the technical stability of online devices led together probably to a time risky behavior. This statement is strengthened by the number of students submitted after deadline. There was even one student who submitted around one hour after the deadline. This late student explained this delay later with a complete internet blackout of his online device. Another typical technical problem was that students try to send photographs with big 
data size up to $20 \mathrm{MB}$. In consequence, worksheets delivered later than 10 minutes after deadline are not counted in further evaluation. For this, these late students cannot pass, even if they got a high score in the former three semester worksheets. In general, a correlation between the exam performance and time of submission cannot be made, because in several cases a delay in submission is caused by technical problems and the large size of sent data files.

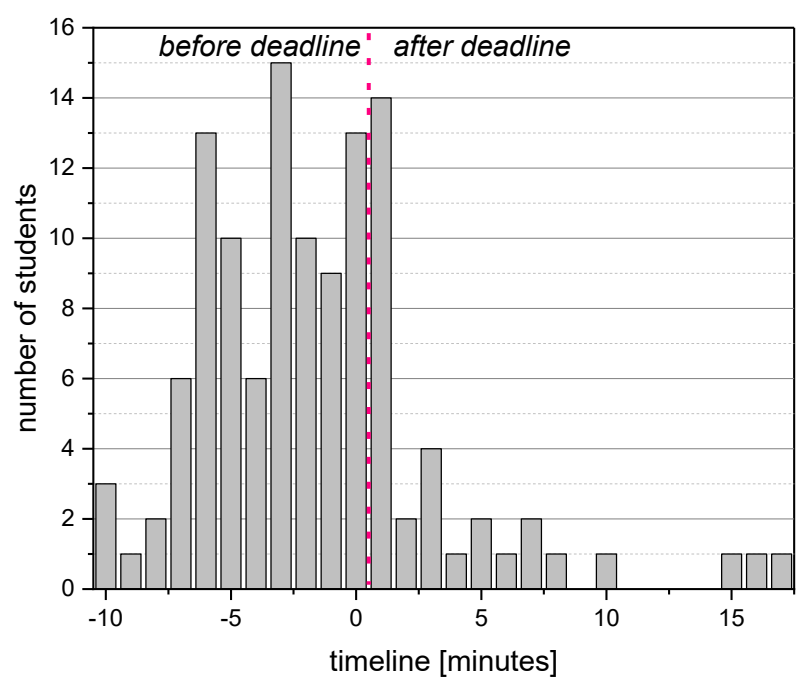

Fig. 9 Development of submitted final worksheets in relation to the deadline for submission. Compared are the numbers of students who submitted the worksheets according to a given timeline.

The final worksheet contains three questions mentioned in Table 3. The first two questions are related to fiber-dye interaction, while the last one is related to printing techniques. In the first question, the chemical structures of three high-performance fibers are shown, which were previously not discussed in the lecture. On basis of these structures, the students have to suggest appropriate dyes for these types of fibers. To solve this task, the students have to identify the main functional groups to which an applied dye can interact, so they have to understand and transfer the principle of fiber-dye interaction. The three shown high-performance fibers are polyvinyl alcohol, polyphenylene sulfide and polyetheretherketone. Most students realize that polyvinyl alcohol contains hydroxy groups and could be dyed by reactive dyes. In a certain way this is similar to the dyeing of cotton which contains as cellulosic fiber as well a big number of hydroxy groups. For polyphenylene sulfide and polyetheretherketone, lower numbers of correct answers are submitted. Surprisingly, some students compare polyphenylene sulfide with wool fibers, because of the presence of sulfur in the chemical structures.

Table 3. Short description of the three questions in the final worksheet. Additional to the questions also the intention for the main understanding is given.

\begin{tabular}{lll}
\hline No. Question & Intention of understanding \\
\hline 1 & $\begin{array}{l}\text { Chemical structures of three different high } \\
\text { performance fibers are shown - a dye stuff of } \\
\text { different class useful for the fibers has to be } \\
\text { suggested. }\end{array}$ & $\begin{array}{l}\text { fiber dye interaction, transfer of knowledge to } \\
\text { unknown fibers }\end{array}$ \\
$\mathbf{2}$ & $\begin{array}{l}\text { Chemical structures of two different types of } \\
\text { special polyamides are shown - which polyamide } \\
\text { can be more easily dyed with an acid dye and } \\
\text { why? }\end{array}$ & $\begin{array}{l}\text { fiber dye interaction, categorization of fibers from } \\
\text { the same type }\end{array}$ \\
$\begin{array}{l}\text { Three different images are shown, which should } \\
\text { be printed in mass production for cotton T-shirts - } \\
\text { suitable dye stuff, printing styles and printing } \\
\text { techniques have to be suggested. }\end{array}$ & $\begin{array}{l}\text { relation of ideal printing styles/techniques to the } \\
\text { aimages and product }\end{array}$ \\
\end{tabular}


For the second question, the chemical structures of two different special polyamide fibers are shown and the students have to decide and give arguments, which of both fibers can be better dyed with an acid dye. This question was probable the most difficult one, because the students have to understand that one type of polyamide has a stronger hydrophobicity compared to the other one. For this, there is a different up-take of a water-based dye bath and a different affinity to the hydrophilic molecules of the acid dyes. The third question is related to printing. Here, three images were shown and the students have to suggest appropriate printing styles and techniques to realize these images on cotton for mass production. One main task was to identify that both simple images are best realized by conventional printing styles as direct or discharge printing, while a complicated photo is better realized by digital printing. Most students were able to solve this task well.

\section{Student Feedback}

As part of a didactic evaluation, the students were encouraged to fill out a questionnaire related to this lecture. This questionnaire is online, anonymous and performed after the sixth lecture during the semester. For this, the questionnaire gives a good overview on the situation in the lecture in the middle of the semester. However, it gives not student opinions in the end of the semester or after the examination is made. These types of questionnaires are obligatory used for each lecture every second year. The students can answer the questions with a rating from 1 (best) to 5 (worst). The rating 1 stands for the statement "strongly agree" and the rating 5 is for "strongly disagree". Beside the fixed questions, also free answers and statements to positive and negative aspects of the lecture can be made by the students. The questions of the questionnaire are given in Figure 10. Here, also the results are given as average of the ranking all students gave. Compared are the answers of the current digital lecture with the average rankings of two evaluations made for the same conventional lecture in the years 2016 and 2018.

For all questions, the students give better or equal rankings for the digital lecture compared to the conventional lectures given in last years. The overall satisfaction with the lecture is significantly improved. Main improvements are stated for the teaching style and the structure of the course. So according to the student opinions in the middle of the semester, the digital lecture is a format which is advantageous compared to former conventional lectures. However, it has to be mentioned that other digital lectures in this semester got an overall better ranking - especially lectures given in master courses. The general better ranking of master courses is probably caused by smaller numbers of students and special master topics which are more related to the job market and current research.

Beside the given questions, further student remarks give a more detailed view on positive and negative aspects. Positively mentioned are especially the sending of the notes after each lecture as pdf-file and the opportunity to do the worksheets as part of the exam already during the semester.

However, the points the students request for improvements are more of interest. Requested was the stronger use of videos, pictures and practical examples from industry during the lecture, because video was only used during one lecture event. The use of a recommended book and journal papers instead of an exclusively prepared script was also negatively mentioned. In fact, in current bachelor courses, the students are used to get a script paper which the lecturer made especially for them and hands them over in the beginning of a conventional semester. One student remarks a high workload in relation to the book and the journal papers, because the reading is quite time consuming compared to the working with a script.

There is, of course, the challenge that during the digital semester the workload of the students can be underestimated by the lecturer, so an overflow with book and paper recommendations can happen. However, in the current finishing lecture only one book is recommended and the number of recommended papers is also limited. In fact, it is also part of the teaching process to read and select information from standard literature. Finally, a compromise has to be made. 


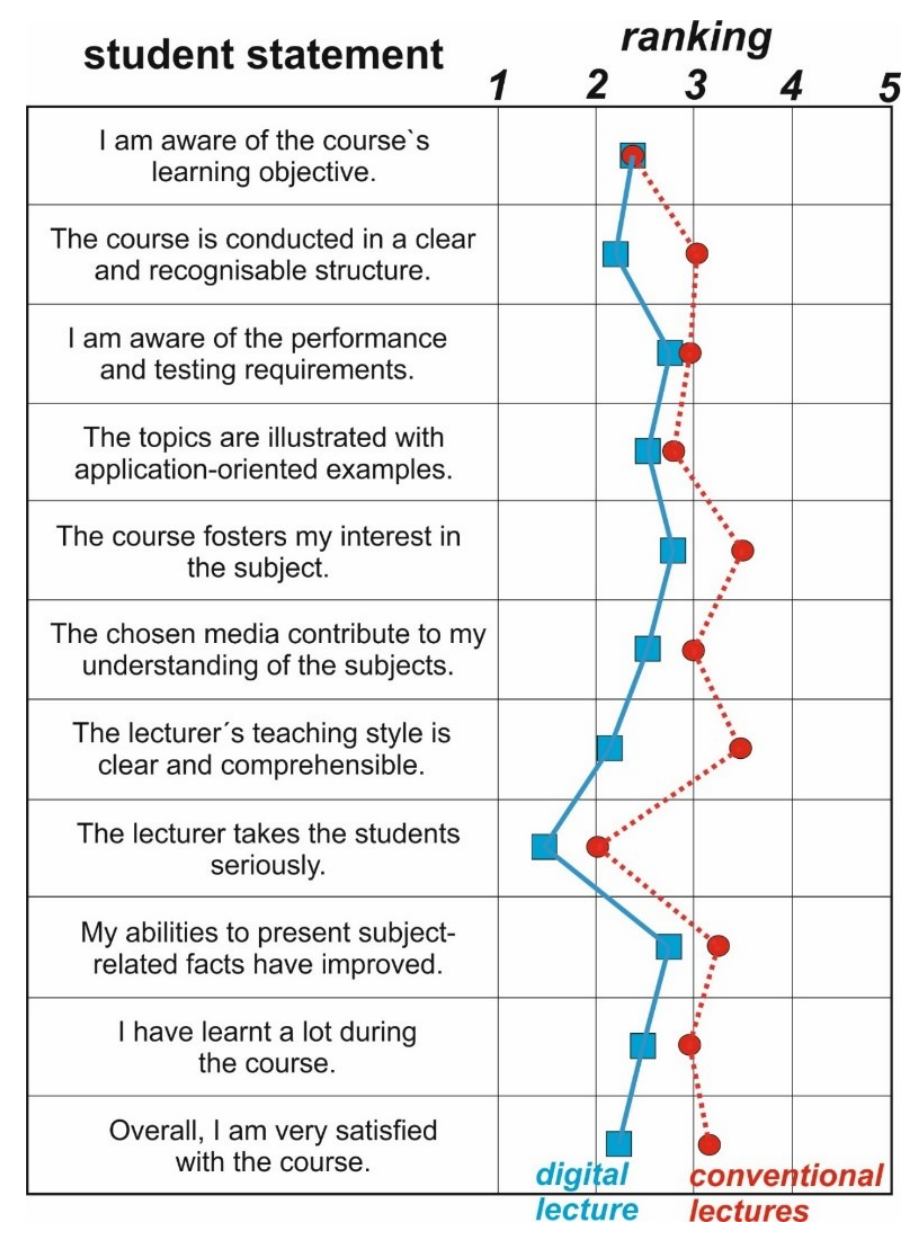

Fig. 10 Results of anonymous student questionnaire. Comparison of answers for the actual digital lecture and average values for conventional lectures given during recent years. The ranking of answers is in the range 1 (best) to 5 (worst).

\section{Results \& Discussion}

Just by viewing the simple numbers of registrations, participations and passed students, it is clear that this digital lecture and exam were successful (Figure 1). This statement is strengthened by the results of the student feedback evaluation (Figure 10). The number of participating and passed students is doubled compared to the long year average number. The marks gained are in the expected range (Figure 2). For this, it was possible to include a big number of students, and even older students of higher semesters joined lecture and exam. These older students often live in other cities or even countries, so the digital format is for them a real advantage, because they do not need to travel. Nevertheless, there are two serious issues of concern. First, the quite small number of participating students from the 3rd semester (only 69 students compared to the official number of 86). Probably these students get lost in the conditions of corona situation which accompanying them nearly their complete student duration. The second point of concern is the time management of the students during digital exam. They submit their worksheets in the last few minutes before the deadline and have a strong trust in the technical process of digital submission. For example, some students submit files with their worksheet results containing a size of up to $20 \mathrm{MB}$ and they believe that these files are transported fast and without problems.

Another important issue is the high work load for the teaching professor for a digital lecture compared to a conventional one. This high workload is not caused by the digital lecture itself. It is caused by the worksheet and the digital exam. The evaluations take nearly five-times longer in comparison to the earlier done conventional written examination. Also, the organization and identification of incoming emails lead to a significant time consumption. If the higher time effort per student and the higher number 
of participating students are considered, it can be realized that the success of the digital format has a certain prize.

The final questions are, whether such a format is also suitable in after corona times, and which elements make the digital format successful? Probable one important tool are the worksheets distributed during the semester. By these worksheets, the students achieved already some points for the exam, so they are motivated to join the final exam. Also important are the collections of questions, notes and statements during the lecture and distributing them to all registered students by email, so no issues get lost.

By view on the technical problems some students faced during the final worksheet and their time risk behavior, this digital format is maybe not so suitable for lectures with younger students in the first two semesters of the curriculum. The main success of the digital format was the high participating rate especially of older students which are often not living around the university town. For this, the digital lecture could be also a useful tool in after corona times. This statement concerns especially lectures where a big number of older students is present which still need to pass only few subjects just before they are able to finish the bachelor study course completely.

\section{Summary \& Conclusion}

A lecture in a bachelor course with more than 100 students is successfully converted to a digital format. The topics of the course are finishing processes, dyeing and printing. Main tools of the digital format are video conferences, the development of a weekly summary and digital worksheets. Challenging are the contact to students by e-mail and the time management of the students especially during the final digital homework. The number of students participating in the exam and students who finally pass the exam are compared with the numbers during the last decade with the same lecture given in conventional style. The number of participating students and passed students is for the digital more than the doubled compared to the long year average for the lecture. The reached marks are in the range of the long year average. For this, it can be concluded that a digital lecture and exam are valuable tools to increase the number of participating students and their success in the exam. These tools could be also used successfully in post-corona times especially for lectures given for experienced students in higher semesters.

\section{References}

[1] Marius Schwarz, Aline Scherrer, Claudia Hohmann, Jonas Heiberg, Andri Brugger and Alejandro NuñezJimenez. 2020. COVID-19 and the academy: It is time for going digital. Energy Research \& Social Science 68, 101884. DOI: https://doi.org/10.1016/j.erss.2020.101684.

[2] Christopher M. Pastore, Yordan Kyosev, F. A. Fassihi and Becky Flax. 2021. Textile education during the 2020 pandemic: experiences in US, South Africa and Germany. COMMUNICATIONS IN DEVELOPMENT AND ASSEMBLING OF TEXTILE PRODUCTS - CDATP 2, 18-33. DOI: 10.25367/cdatp.2021.2.p18-33.

[3] P. Ayu Suci Lestari, Gunawan and dan Syahriani Yulianci. 2020. Effectiveness of online lectures using digital platform during the pandemic COVID-19. Indonesian Journal of Applied Science and Technology 1 (3), 107115.

[4] Olaf Zawacki-Richter. 2021. The current state and impact of Covid-19 on digital higher education in Germany. Hum. Behav. \& Emeg. Tech. 3, 218-226. DOI: https://doi.org/10.1002/hbe2.238.

[5] Thomas Grethe and Boris Mahltig. 2020. Alternative Prüfungsformen im Sommersemester 2020. Die Neue Hochschule DNH 06-2020, 42-45.

[6] Roger H. Wardman. 2018. An Introduction to Textile Coloration. John Wiley \& Sons Ltd., Hoboken.

[7] J. R. Aspland. 1992. Vat dyes and their application. Textile Chem. Color. 24(1), 22-24.

[8] J. R. Aspland. 1992. Practical Application of Sulfur Dyes. Textile Chem. Color. 24(4), 27-31.

[9] Kawee Srikulkit and Pornchai Santifuengkul. 2000. Salt-free dyeing of cotton cellulose with a model cationic reactive dye. Coloration Technology 116(12), 398-402. DOI: https://doi.org/10.1111/j.14784408.2000.tb00017.x.

[10] Wu Hanbing, Hajo Haase and Boris Mahltig. 2020. Cationic pretreatment for reactive dyeing of cotton and its simultaneous antibacterial functionalisation. Tekstilec 63(1), 27-37. DOI: https://doi.org/10.14502/Tekstilec2020.63.27-37. 